\section{SAT0491 CLINICAL FEATURES AND COMPLICATIONS IN A LARGE INTERNATIONAL COHORT OF ANTIMDA5 PATIENTS: A CHALLENGE FOR THE FUTURE}

F. Locatelli ${ }^{1}$, S. Castaneda ${ }^{2}$, G. Zanframundo ${ }^{1}$, A. Meyer $^{3}$, F. lannone ${ }^{4}$, M. Giannini ${ }^{4}$, S. Prieto Gonzalez ${ }^{5}$, C. Scire ${ }^{6}$, M. Govoni $^{6}$, C. Montecucco ${ }^{1}$, F. Furini ${ }^{6}$, J. Vega ${ }^{7}$, H. Lorenz $^{8}$, G. Emmi ${ }^{9}$, I. Villa Blanco ${ }^{10}$, S. Barsotti ${ }^{11}$, R. Neri ${ }^{11}$ M. Mosca ${ }^{11}$, A. Pesci' ${ }^{12}$, G. Dei ${ }^{12}$, M.F. Moraes-Fontes ${ }^{13}$, D. Cammelli ${ }^{14}$, P. Parronchi ${ }^{14}$, B. Biagioni ${ }^{14}$, A. Mathieu ${ }^{15}$, M. Piga $^{15}$, C. Nannini ${ }^{16}$, R. Gerli ${ }^{17}$, E. Bartoloni Bocci ${ }^{17}$, J.E. Fonseca ${ }^{18}$, R. Marques ${ }^{18}$, F. Romero Bueno ${ }^{19}$, L. Damian ${ }^{20}$, M. Belliato ${ }^{21}$, S. De Vita ${ }^{22}$, L. Quartuccio ${ }^{22}$, F. Maurier ${ }^{23}$, J. Cifrian $^{24}$, G. Zampogna ${ }^{25}$, A. Mera Varela ${ }^{26}$, N. Perez Gomez ${ }^{26}$, P. Da Silvaa ${ }^{27}$, C.J. Matos Costa $^{28}$, J. Rojas-Serrano ${ }^{29}$, L. Vazquez $z^{29}$, U. Schneider ${ }^{30}$, E. Feist ${ }^{30}$, I. Cavazzana ${ }^{31}$, F. Franceschini $i^{31}$, G. Cagnotto ${ }^{32}$, I. Chiapparoli ${ }^{1}$, S. BellandoRandone $^{33}$, M. Matucci-Cerinic ${ }^{33}$, R. Caporali ${ }^{1}$, M.A. Gonzalez-Gay ${ }^{34}$, L. Cavagna ${ }^{1}$ on behalf of AENEAS collaborative group. ${ }^{1}$ Rheumatology, University, Irccs Policlinico S. Matteo F, Pavia, Italy; ${ }^{2}$ Rheumatology, University Hospital La Princesa, Madrid, Spain; ${ }^{3}$ Rheumatology, Hautepierre Hospital, Strasbourg, France: ${ }^{4}$ Rheumatology, University, Bari, Italy; ${ }^{5}$ Rheumatology, University Hospital Clinic, Barcelona, Spain; ${ }^{6}$ Rheumatology, AOU S Anna, Ferrara, Italy; ${ }^{7}$ Rheumatology, University Hospital, Alicante, Spain; ${ }^{8}$ Rheumatology, University, Heidelberg, Germany; ${ }^{9}$ Internal Medicine, AOU Careggi, Florence, Italy; ${ }^{10}$ Rheumatology, Sierralana Hospital, Cantabria, Spain; ${ }^{11}$ Rheumatology, AOU, Pisa; ${ }^{12}$ Pneumology, Milano-Bicocca University, HSG, Monza, Italy;

${ }^{13}$ Rheumatology, University Hospital Lisboa Central, Lisboa, Portugal;

${ }^{14}$ Immunology, AOU Careggi, Florence; ${ }^{15}$ Rheumatology, AOU, Cagliari;

${ }^{16}$ Rheumatology, Hospital, Prato; ${ }^{17}$ Rheumatology, University, Perugia, Italy;

${ }^{18}$ Rheumatology, University Hospital Lisboa Norte, Lisboa, Portugal;

${ }^{19}$ Rheumatology, Universiity Hospital J Diaz, Madrid, Spain; ${ }^{20}$ Rheumatology, Cluj Hospital, Cluj, Romania; ${ }^{21}$ ICU2, IRCCS Policlinico S Matteo Foundation, Pavia;

${ }^{22}$ Rheumatology, University Hospital, Udine, Italy, ${ }^{23}$ Rheumatology, HPMetz, Metz, France, ${ }^{24}$ Pneumology, IDIVAL, Santander, Spain; ${ }^{25}$ Rheumatology, Brunico Hospital, Brunico, Italy; ${ }^{26}$ Rheumatology, University Hospital, Santiago de Compostela, Spain; ${ }^{27}$ Rheumatology, Universiity Hospital, Coimbra, Portugal; ${ }^{28}$ Rheumatology, Universiity Hospital, Coimbra, Spain; ${ }^{29}$ Pneumology, INER, Mexico city, Mexico; ${ }^{30}$ Rheumatology, Charite University Hspital, Berlin, Germany; ${ }^{31}$ Rheumatology, AOU, Brescia, Italy, ${ }^{32}$ Rheumatology, Skane University Hospital, Lung, Sweden; ${ }^{33}$ Rheumatology, AOU Careggi, Florence, Italy; ${ }^{34}$ Rheumatology, IDIVAL, Santander, Spain

Background: Anti-MDA5 antibodies are a known set of antibodies observed mainly in dermatomyositis, typically associated with cutaneous involvement, presence and often rapid progression (RP) of interstitial lung disease (ILD) and amyopathic muscle involvement. Despite the increased attention, described cohorts involves only a limited number of cases

Objectives: to define clinical characteristics of a large cohort of anti-MDA5 antibodies positive patients

Methods: Retrospective assessment of anti-MDA5 positive patients from centres referring to our group

Results: 82 anti-MDA5 positive cases (56 females) were collected. In median: onset age was 44 Y (IQR 22.57), diagnostic delay 4 Mo (IQR 1-10), follow-up 13 Mo (IQR 3-43). Fifty-three patients had ILD, that was RP in 24 cases (15 at ILD onset, 9 after ILD onset). Fifthteen ILD patients were admitted in Intensive Care Unit (ICU): 4 were treated with Extracorporeal-Membrane-Oxygenation, 7 with mechanical-invasive and 2 with mechanical-non-invasive ventilation. Forthy-nine patients had muscle involvement (39 symptomatic), 42 arthritis, 54 cutaneous involvement, 9 history of malignancy. Twelve patients died (ILD=7, ILD and sepsis=3, neoplasia $=1$, not specified $=1$ ), 7 of those in ICU

Conclusions: In our cohort, ILD was the most frequent finding. A RP of ILD was common, occurring also in ILD with symptomatic/chronic onset. The low rate of survival in ICU raised the problem of follow up and early treatment of ILD. In our cohort arthritis was common and muscle involvement mainly symptomatic. Finally, the high percentage of observed malignancies suggests a careful neoplastic screening and follow up

\section{REFERENCE:}

[1] Labrador-Horrillo M, et al. J Immunol Res 2014;2014:290797.

Disclosure of Interest: None declared

DOI: 10.1136/annrheumdis-2018-eular.2827

\section{SAT0492 PREVALENCE OF THE METABOLIC SYNDROME IN PATIENTS WITH SYSTEMIC SCLEROSIS}

G. Cuomo, F. Danzo, F. Masini, R. Ferrara, E. Pinotti, C. Romano, L.E. Adinolfi. UOC Medicina Interna, Universita Degli Studi Della Campania, Napoli, Italy

Background: The metabolic syndrome is an independent risk factor for ischaemic heart disease. Patients with systemic lupus eriythematosus have un increased prevalence of the metabolic syndrome. ${ }^{1}$ There are no controlled studies of the metabolic syndrome in patients with SSc.

Objectives: To compare the prevalence of the metabolic syndrome in patients with SSc and controls and to evaluate its relationship to activity and severity of disease.

Methods: Methods: 50 consecutive patients with SSc (45 female, median age 48; range 20-72) and 50 controls (patients whit fibromyalgia) (45 female, median age 46; range 25-72) were studied. The prevalence of the metabolic syndrome was compared in patients and controls using the National Cholesterol Education Program Adult Treatment Panel III (NCEP-ATPIII): central obesity: waist. $102 \mathrm{~cm}$ in men and. $88 \mathrm{~cm}$ in women; ${ }^{2}$ hypertriglyceridaemia: $>150 \mathrm{mg} / \mathrm{dl} ;^{3}$ low HDL, $40 \mathrm{mg} / \mathrm{dl}$ in men and, $50 \mathrm{mg} / \mathrm{dl}$ in women; ${ }^{4}$ high blood pressure:>130/85 mm Hg or use of drugs for high blood pressure; and ${ }^{5}$ high fasting glucose $>110 \mathrm{mg} / \mathrm{dl}$, and associations with activity and severity of the disease were examined.

Results: The metabolic syndrome was present in $24 \%$ of patients and in $30 \%$ of controls subjects $(p>0.05)$. Among patients with SSc, the metabolic syndrome was significantly associated with higher value of ESR (ESR $>30)(5 / 7$ vs $4 / 34$; $p=0.027)$. Neither disease activity nor severity scores were associated with the metabolic syndrome

Conclusions: Patients with SSc have a lower prevalence of the NCEP-ATPIIIdefined metabolic syndrome than controls. This result may help to justify the coronary prevalence in SSc patients similar to that of the general population. ${ }^{2-3}$

\section{REFERENCES}

[1] Bengtsson AA, et al. PLoS One 2016 Jul;21;11(7).

[2] Hattema ME, et al. Rheumatology 2008;45:578-83.

[3] Akram MR, et al. Rheumatology 2006;45:1395-8.

Disclosure of Interest: None declared

DOI: 10.1136/annrheumdis-2018-eular.4309

\section{SAT0493 PLASMA LEVELS OF HSP90 ARE INCREASED IN INTERSTITIAL LUNG DISEASE AND SKIN FIBROSIS IN PATIENTS WITH SYSTEMIC SCLEROSIS}

H. Storkanova ${ }^{1}$, S. Oreska ${ }^{1}$, M. Spiritovic ${ }^{1,2}$, B. Hermankova ${ }^{1,2}$, K. Pavelka $^{1}$ J. Vencovsky ${ }^{1}$, J.H. Distler ${ }^{3}$, L. Senolt ${ }^{1}$, R. Becvar ${ }^{1}$, M. Tomcik ${ }^{1}$. ${ }^{1}$ Department of Rheumatology, 1st Medical Faculty, Charles University, Institute of Rheumatology, ${ }^{2}$ Department of Physiotherapy, Faculty of Physical Education and Sport, Charles Univesity, Prague, Czech Republic; ${ }^{3}$ Department of Internal Medicine III and Institute for Clinical Immunology, University of Erlangen-Nuremberg, Erlangen, Germany

Background: Our previous study demonstrated that Heat shock protein 90 (Hsp90) is overexpressed in the skin of patients with systemic sclerosis (SSc), in cultured SSc fibroblasts and preclinical models of SSc in a TGF- $\beta$ dependent manner. We showed that $\mathrm{Hsp} 90$ is a regulator of TGF- $\beta$ signalling and its inhibition prevents the stimulatory effects of TGF- $\beta$ on collagen synthesis and dermal fibrosis in three preclinical models of $\mathrm{SSc}^{1}$.

Objectives: The aim of this study was to evaluate Hsp90 in the circulation of SSc patients and characterise its potential association with skin changes and SScrelated features.

Methods: A total of 91 patients (78 females; mean age 52.7; disease duration 6.0 years; diffuse cutaneous (dc)SSc/limited cutaneous (Ic)SSc=38/53) who met the ACR/EULAR 2013 classification criteria for SSc and 85 age-/sex- matched healthy individuals were included. Plasma Hsp90 was measured by ELISA (eBioscience, Vienna, Austria). Data are presented as median (IQR, 25.-75. percentile).

Results: Plasma Hsp90 levels were increased in SSc patients compared to healthy controls [12.5 (9.6-17.9) vs. $9.9(7.9-12.6) \mathrm{ng} / \mathrm{mL}, \mathrm{p}=0.001]$, but no difference between IcSSc and dcSSc was detected [13.1 (9.4-18.1) vs. 11.5 (9.517.5) $\mathrm{ng} / \mathrm{mL}, \mathrm{p}=0.316]$. Hsp90 levels in all patients positively correlated with CRP 
$(r=0.313, p=0.006)$. Furthermore, Hsp90 was increased in patients with interstitial lung disease (ILD) compared to those without ILD [12.8 (10.2-17.9) vs. 10.3 (8.616.6) $\mathrm{ng} / \mathrm{mL}, \mathrm{p}=0.045]$ and was negatively associated with functional parameters of ILD: FVC ( $r=-0.299, p=0.011)$, FEV1 $(r=-0.256, p=0.031)$, DLCO ( $r=-0.303$, $\mathrm{p}=0.009)$ and $\mathrm{SpO}_{2}(\mathrm{r}=-0.317, \mathrm{p}=0.038)$. In addition, only in patients with dcSSc, Hsp90 levels positively correlated with the mRSS ( $r=0.437, p=0.006)$. Hsp90 concentrations were not significantly affected by other main clinical parameters of SSc.

Conclusions: We demonstrated higher plasma levels of Hsp90 in SSc patients compared to healthy controls. Concentrations of extracellular Hsp90 increase with higher inflammatory activity, with deteriorated lung functions in ILD and also with the extent and severity of the skin involvement in patients with diffuse cutaneous SSc. These data further highlight the role of $\mathrm{Hsp90}$ as a significant regulator of fibroblast activation and tissue fibrosis in SSc.

\section{REFERENCE:}

[1] Tomcik M, et al. Ann Rheum Dis 2014;73(6):1215-22.

Acknowledgements: Supported by AZV - 16-33542A and SVV - 260373 Disclosure of Interest: None declared

DOI: 10.1136/annrheumdis-2018-eular.6437

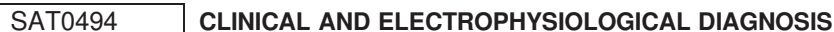 OF SYMMETRICAL POLYNEUROPATHY IN SYSTEMIC SCLEROSIS: STUDY FROM A SINGLE TERTIARY CENTRE IN MALAYSIA}

T. Balaikerisnan', K.J. Goh ${ }^{2}$, L.P. Ramanaidu ${ }^{2}$, J. Raja ${ }^{1} .{ }^{1}$ Division of Rheumatology, Department and Faculty of Medicine; ${ }^{2}$ Division of Neurology, Department and Faculty of Medicine, University of Malaya, Kuala Lumpur, Malaysia

Background: Peripheral neuropathy (PN) in systemic sclerosis (SSc) is an under recognised non-lethal burden with its prevalence between $0.01 \%$ to $28 \%{ }^{1}$. Previous studies have been limited by small sample size, variable diagnostic criteria and different populations studied.

Objectives: The aim of this study is to determine the prevalence of symmetrical $\mathrm{PN}$ in SSc patients and to identify the associated factors that can predispose to $\mathrm{PN}$ in SSc.

Methods: 59 SSc patients from University Malaya Medical Centre participated in this cross-sectional study. Clinical symptoms/signs of PN were assessed using modified Total Neuropathy Score (TNS). Nerve conduction studies (NCS) were carried out on the upper and lower limbs. Diagnosis of symmetrical polyneuropathy was defined as combined TNS score $\geq 2$ and abnormal NCS parameters in at least 2 nerves including the sural ${ }^{2}$. Focal neuropathy was defined as abnormal NCS of a nerve other than the sural nerve (radial, median, ulnar, common peroneal).

Results: Majority were females $(54,91.5 \%)$ and had limited cutaneous SSc $(44,74.6 \%$ ). Mean age was 55.7 (SD \pm 13.1 ) years while mean duration of disease (non-Raynaud's disease onset) was 8.74 years (SD \pm 8.09 ) (range 1 to 44 years). Out of 59 patients, $38(64.4 \%)$ had TNS $\geq 2$. On NCS, $17(31.5 \%)$ and $12(22.2 \%)$ had findings of symmetrical polyneuropathy and focal neuropathy respectively. A total of $14(23.7 \%)$ SSc patients were diagnosed to have symmetrical polyneuropathy. Lower haemoglobin level was significantly associated with symmetrical polyneuropathy $(p=0.047)$ after adjustment for potential confounding variables. Serum vitamin B12 was normal in all subjects with symmetrical polyneuropathy. No correlation was seen in SSc related comorbidities (diabetes mellitus and kidney disease), serum fasting blood sugar, creatinine and MCV, as well as disease markers such as skin fibrosis (MRSS skin score), specific organ manifestations, Raynaud's or vasculopathy, SSc specific auto-antibodies and treatment received.

\begin{tabular}{|c|c|c|c|c|}
\hline \multirow[t]{7}{*}{ Demography } & & $\begin{array}{c}\text { No polyneuropathy } n=45 \\
(76.3 \%)\end{array}$ & $\begin{array}{l}\text { Polyneuropathy } n=14 \\
(23.7 \%)\end{array}$ & $\begin{array}{c}\mathrm{p} \\
\text { value }\end{array}$ \\
\hline & $\begin{array}{l}\text { Mean age (y.o } \\
\pm)\end{array}$ & $53.6 \pm 13.22$ & $62.57 \pm 10.69$ & 0.025 \\
\hline & $\begin{array}{ll}\text { Sex } & \text { Female } \\
\mathrm{n}(\%) & \end{array}$ & $45(76.3)$ & $14(23.7)$ & 0.325 \\
\hline & $\begin{array}{ll}\text { Male } 5(100)\end{array}$ & $0(0)$ & & \\
\hline & $\begin{array}{l}\mathrm{BMI} \mathrm{kg} / \mathrm{m}^{2} \\
\text { (mean) }\end{array}$ & $22.9 \pm 5.94$ & $21.0 \pm 5.13$ & 0.736 \\
\hline & Diffuse SSc & $10(22.2)$ & $4(28.5)$ & 0.722 \\
\hline & Limited SSc & $35(77.7)$ & $10(71.4)$ & 0.316 \\
\hline \multicolumn{2}{|c|}{ MRSS score (mean) } & $10.29 \pm 8.02$ & $8.36 \pm 4.23$ & 0.594 \\
\hline \multicolumn{2}{|c|}{ SSc duration (mean) } & $8.97 \pm 8.78$ & $8.00 \pm 5.51$ & 0.803 \\
\hline \multicolumn{2}{|c|}{ Haemoglobin (mean) (g/L) } & $12.36 \pm 1.33$ & $11.2 \pm 1.25$ & 0.010 \\
\hline \multirow{2}{*}{\multicolumn{2}{|c|}{$\mathrm{MCV}>97(\mathrm{fl})$}} & $4(8.9)$ & $3(21.4)$ & 0.175 \\
\hline & Creatinine (median) (umol/L) & $55 \pm(I Q R$ 45-60) & $61.5 \pm($ IQR $49-75)$ & 0.111 \\
\hline
\end{tabular}

\begin{tabular}{lcrc}
$\begin{array}{l}\text { Fasting blood sugar (mean) } \\
\text { (mmol/L) }\end{array}$ & $4.32 \pm 1.16$ & $5.67 \pm 2.46$ & 0.095 \\
ESR (mean) (mm/hr) & $33.7 \pm 20.65$ & $44.23(19.6)$ & 0.068 \\
\hline
\end{tabular}

\section{Neurological Components}

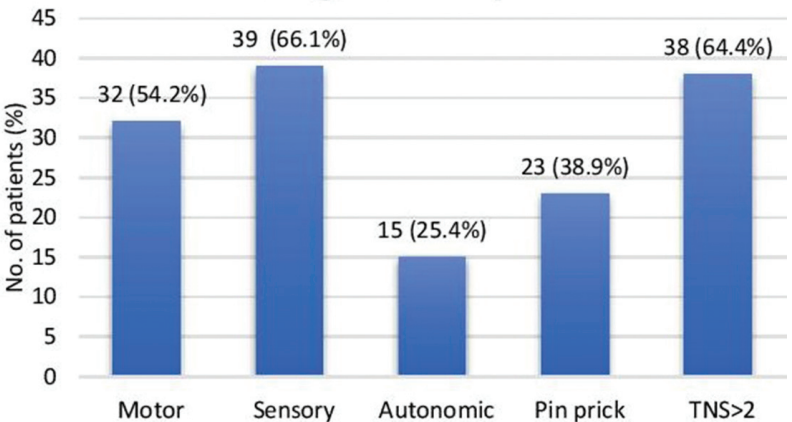

Conclusions: The prevalence of PN in a Malaysian SSc cohort is similar to other studies (23.7\%). Lower haemoglobin level was significantly associated with symmetrical polyneuropathy in SSc.

\section{REFERENCES:}

[1] Paik JJ, et al. Symptomatic and Electrodiagnostic Features of Peripheral Neuropathy in Scleroderma. Arthritis Care Res (Hoboken) 2016;6(8):1150 57.

[2] England JD, et al. Distal symmetrical polyneuropathy: a definition for clinical research. A report of the American Academy of Neurology, the American Association of Electrodiagnostic Medicine, and the American Academy of Physical Medicine and Rehabilitation. Arch Phys Med Rehabil 2005 Jan;86(1):167-74.

Disclosure of Interest: None declared

DOI: 10.1136/annrheumdis-2018-eular.1874

\section{SAT0495 PLASMA D-DIMER CONCENTRATION, MACROVASCULAR DISEASE AND MORTALITY IN PATIENTS WITH SYSTEMIC SCLEROSIS}

J.J. Alegre-Sancho, M. Robustillo-Villarino, M. Aguilar-Zamora, L. Montolio-Chiva E. Valls-Pascual, D. Ybáñez-García, À. Martínez-Ferrer, I. Torner-Hernández, V. Núñez-Monje, A.V. Orenes-Vera, A. Sendra-García. Rheumatology, Hospital Universitario Doctor Peset, Valencia, Spain

Background: Plasma d-dimer (DD) has proven to be a reliable marker of a systemic prothrombotic state and its measurement might be helpful in predicting cardiovascular events and even mortality across a broad variety of diseases. An association between high levels of DD and macrovascular disease, diffuse cutaneous involvement and active disease has been suggested in patients with SSc. Objectives: To determine the usefulness of DD measurement as a marker of macrovascular disease and mortality in patients with SSc. To explore its relation with other features and biomarkers of SSc.

Methods: Descriptive ambispective observational study. We included, consecu tively from 2010 to 2015 , SSc patients controlled in a tertiary hospital. We gathered demographic, clinical, and analytical variables, including DD levels measured by turbidimetric immunoassay (ACL TOP 700 CTS, Werfen Spain). Other variables were collected retrospectively from the electronic medical record. We explored the extracranial branches of the carotid artery (ESAOTE MyLab XV70, 7-12 MHz linear probe, software ${ }^{\mathrm{RF}} \mathrm{QIMT}$ ) measuring intima media thickness (IMT) by radiofrequency, and the presence of atheroma plaques, as per the Mannheim consensus, was registered. The ankle-brachial index $(A B I)$ was measured by a Vascular Surgeon. We considered an IMT>900 $\mu$ and/or presence of atheroma plaque and/or an $\mathrm{ABI}<0.9$ as macrovascular damage. We prospectively collected mortality until dec-2017. Statistical analysis was performed using SPSS 17.0 software.

Results: 115 patients where included consecutively, of which finally 100 were studied ( 91 women, 9 men), with a mean age of 60.2 years (SD 15). Mean SSc evolution time was 13.9 years (SD 11.2). LSSc was most frequently diagnosed $(50 \%)$, followed by DSSc $(18 \%)$, SSc without scleroderma $(17 \%)$, overlap syndrome (9\%) and pre-SSc (6\%). $37 \%$ of patients were hypertensive, $45 \%$ dyslipidemic, and $7 \%$ were diabetic. Overall, $40 \%$ had macrovascular damage. The mean values of DD were $437.6 \mathrm{ng} / \mathrm{mL}$ (SD 683.5), $60 \%$ of the patients having levels of DD (>250 ng/mL). During follow up, there were 16 deaths, $50 \%$ due to vas cular events. Baseline high levels of plasma DD were associated to macrovascular damage and ischaemic digital ulcers, together with advanced age, arthritis, inflammation biomarkers, HTA, sPAP, lower DLCO \% and coexistence of 